\title{
La Iglesia católica-romana no es la verdadera Iglesia de Cristo
}

\author{
José Ignacio González Faus, \\ Cristianisme i Justícia, \\ Barcelona
}

Nadie se asuste por el título: es lo que dijo el Vaticano II. La verdadera Iglesia de Cristo "subsiste" en la Iglesia católica, pero no se identifica con ella (LG 8). Esa enseñanza es precisamente, y significativamente, la que con más afán pretenden desmontar los que no aceptan el Vaticano II.

\section{Del ayer conciliar a la crisis de hoy}

Por eso, puede ser bueno comenzar enumerando algunos rasgos rápidos, pero literales, de lo que el pasado concilio enseñó sobre la Iglesia, y que fundamentan el aparente escándalo de mi título. Algunos elementos constitutivos de la verdadera Iglesia de Cristo, espigados del concilio, serían los siguientes.

1.1. La Iglesia como misterio es el pueblo de Dios. Una afirmación típicamente neotestamentaria recuperada por Vaticano II y que hoy desautorizan los enemigos del concilio. Vivida en serio, esta tesis lleva a una desclericalización de la Iglesia porque el misterio de la Iglesia no es "el poder sagrado" (o "jerarquía", que es una palabra ausente del Nuevo Testamento), sino esa comunión de todos "los santos y llamados", por usar una designación neotestamentaria. Ese misterio que los santos padres formularon como "bodas" de Dios con la humanidad, recogiendo la alusión paulina a la unión conyugal como referida "a Cristo y su Iglesia" (Ef 5, 32), tras haber enunciado que ya no hay barreras entre los hombres y que "todos" (judíos y gentiles) son llamados a ese pueblo.

De ese (y para ese) pueblo de Dios brotan algunos servicios o "ministerios". Pero estos no constituyen el misterio de la Iglesia, aunque participen de él si realizan la inversión evangélica de la pagana sacralidad del poder en sacralidad del servicio. Como consecuencia de esa afirmación, se da el siguiente punto. 
1.2. La Iglesia es una comunión, a semejanza de la Trinidad. "Reunida por la unidad del Padre y del Hijo y del Espíritu Santo" (LG 4; ver todos los números del 2 al 4). $Y$ en otro momento, hablando de la unidad de los cristianos: "El supremo modelo y supremo principio del misterio de la Iglesia es la unidad de un solo Dios en la Trinidad de personas, Padre, Hijo y Espíritu Santo" (UR 2).

Hoy se rechaza también (o mejor dicho, se aparca) esa imagen eclesiástica de la Trinidad, sustituyéndola por la "potestad", y se deforma así la noción de comunión, identificándola con la simple sumisión a la curia romana. En el fondo persiste aquí la gran tentación arriana del cristianismo, que siempre tuvo repercusiones eclesiásticas: los obispos de Nicea eran casi todos arrianos porque preferían el poder no compartido de los emperadores a la comunión del ser de Dios, donde todos son "co-iguales, consustanciales y coeternos".

1.3. La Iglesia es, sobre todo, servicio. "Instituida no para dominar, sino para servir" (AOH 7), "íntima y realmente solidaria del género humano y su historia (GS 1), "deseosa de ofrecer al género humano su sincera colaboración para lograr la fraternidad universal" (GS 3), consciente de que necesitará "la ayuda de todos los hombres, sean creyentes o no, porque no siempre tiene a mano la respuesta a cada cuestión" (GS 33.43.44).

No creo que sea exagerado decir que la Iglesia romana de hoy no actúa como solidaria del género humano ni cree necesitar la ayuda de nadie (ni siquiera de los de dentro), y busca imponer su verdad por la fuerza de la exclusión, en vez de proponerla como quien sabe que la verdad solo se impone "por la fuerza de ella misma que penetra suave y fuertemente en los espíritus" (DH 1). Todo esto la convierte no en servicio, sino en "autoservicio", en un eclesiocentrismo que acaba siendo "curiocentrismo".

1.4. Para ese servicio, la Iglesia necesita una renovación constante. "Llamada por Cristo a esa perenne renovación de la que ella, en cuanto institución terrena y humana, necesita constantemente" (UR 6). Hoy, en cambio, la curia romana se ha negado a toda reforma: comenzando por la propia reforma de esa curia que tan duramente reclamó el Vaticano II, y que los curiales impidieron realizar a Pablo VI. Y siguiendo por las otras reformas pedidas por el Vaticano II, ante cuya necesidad se alega que "ha pasado el tiempo de los experimentos".

1.5. La Iglesia de Dios es una "iglesia de iglesias", según la precisa expresión de J. M. Tillard. Porque cada iglesia local no es una "parte" de la Iglesia universal, sino un rostro de la total "Iglesia de Dios que está en..."'. Vaticano II sustituyó la designación de las iglesias locales como "partes" de la Iglesia universal (presentada por la curia romana) y habló de "iglesias particulares formadas a imagen de la Iglesia universal, en las cuales y por las cuales existe la única Iglesia

1. La Iglesia de Dios que está en Corinto, o la Iglesia de los tesalonicenses, o los amados y santos de Dios que están en Roma o en Filipos... 
católica" (LG 23). Añadiendo que cada obispo "ejerce su régimen pastoral sobre la porción del pueblo de Dios que le ha sido confiada", rehuyendo también aquí la palabra partes.

Ello implica que los obispos no son meros peones del ajedrez romano, sino verdaderos responsables primarios de sus comunidades, aunque a esa responsabilidad particular pertenece también la obligación de comunión con las demás iglesias locales, a través del ministerio unificador del sucesor de Pedro. Aquí se fundamentaba también la colegialidad episcopal: el papa no es una especie de "párroco universal", sino un corazón que activa y unifica todos los órganos y funciones del cuerpo, pero sin pretender actuar él como cabeza o como estómago, o como brazos...

Tampoco me parece exagerado afirmar que este es uno de los puntos en que más distancia hay entre la enseñanza del Vaticano II y la práctica de los años posteriores.

1.6. El elemento vivificador de la Iglesia es el Espíritu del que Vaticano II enseña que "para que incesantemente nos renovemos en Cristo, nos concedió participar de su Espíritu, que siendo uno mismo en la cabeza y en los miembros, de tal forma vivifica, unifica y mueve todo el cuerpo, que su operación pudo ser comparada por los santos padres con el servicio que realiza el principio de la vida (o alma) en el cuerpo humano" (LG 7). Por eso, "a los que presiden la Iglesia les compete sobre todo no apagar el Espíritu, sino probarlo todo y retener lo bueno" (LG 12).

Hoy tienen muchos la impresión de que la Iglesia oficial ha apagado el Espíritu llevada por el miedo, pretendiendo apropiarse de él en exclusiva y renunciando a probarlo todo para quedarse con lo bueno. De resultas de lo cual no hay un mismo espíritu en la cabeza y en los miembros porque no se busca unificar la diversidad mediante el diálogo y la comunión, sino mediante la imposición formal de una parte sobre las otras.

1.7. El Espíritu era llamado en la liturgia antigua "padre de los pobres". Por eso, si las tesis anteriores podrían hacer temer una excesiva dispersión o pluralidad en la Iglesia, el Vaticano II sabe, con el Nuevo Testamento, que como elemento unificador fundamental, la Iglesia abraza a todos los afligidos. El concilio dice exactamente que la Iglesia "a semejanza de Cristo, que fue enviado a evangelizar a los pobres, sanar los corazones contritos y buscar lo perdido, abraza a todos los afligidos por la debilidad humana, más aún: reconoce en los pobres y en los que sufren la imagen de su Fundador y pretende servir en ellos a Cristo" (LG 8).

Hoy, la Iglesia romana no parece ni de lejos Iglesia de los pobres, sino una Iglesia de los ricos con beneficencia hacia los pobres. Desde aquí se desautoriza como reduccionistas o marxistas a todos los que hacen una opción radical por los pobres, sin temer en absoluto lo que temía el Vaticano II: "Que imitemos a aquel 
rico que se despreocupó por completo del pobre Lázaro" (GS 27). Nadie que la vea desde fuera pensará hoy que "los gozos y esperanzas, las tristezas y angustias de los hombres de hoy, sobre todo de los más pobres y de los que sufren, son gozos y esperanzas, tristezas y angustias de la Iglesia" (GS 1, 1); ni siquiera que la Iglesia intenta eso aunque no sepa conseguirlo.

Estas siete tesis dan contenido a la definición de la Iglesia como "sacramento de salvación" (LG 1, 1), preferida por el concilio. Pero de ellas se siguen también tres juicios sobre nuestra práctica eclesial.

1.8. De resultas de todas estas infidelidades, la Iglesia romana no consigue ser hoy "sacramento de salvación" porque no aparece en modo alguno como una señal eficaz (sacramento) de la comunión de todos los hombres entre ellos y con Dios. Vaticano II se propuso ante todo recuperar esta significatividad de la Iglesia que aspira a ser escuchada por la importancia y el significado de lo que dice, pero no por apelaciones a poderes sobrenaturales extrínsecos.

1.9. La Iglesia no está por encima de la palabra de Dios. Las iglesias de la reforma acusan muchas veces a la Iglesia romana de ponerse a sí misma por encima de la Palabra. Vaticano II rechazó esa acusación y proclamó que la Iglesia es servidora de la Palabra: el magisterio "no está por encima de la palabra de Dios, sino a su servicio, no enseñando sino lo que ha sido transmitido" (DV 10). Pero luego se recupera lo negado afirmando que solo Roma tiene derecho a interpretar la Palabra, negando toda posibilidad de una interpretación objetiva (aunque incompleta) que pueden dar las ciencias bíblicas.

Un increíble ejemplo muy gráfico de esta pretensión es lo que ocurrió en el s. XVI con la Biblia de Sixto V, quien se arrogaba poder incluso para fijar el texto de la Escritura, porque "con el especial privilegio de Dios concedido a esta sede apostólica, podemos decidir entre las diversas lecturas posibles la que mejor corresponde a la verdad ortodoxa"2.

Y otro ejemplo más cercano a nosotros hoy puede ser el tema del ministerio de la mujer. Aun sin tomar postura ante esta cuestión, lo decisivo es que, mientras los mejores estudiosos de la Escritura concluyen que en ella no hay objetivamente argumentos decisivos contra el ministerio femenino, Roma desoye todas esas interpretaciones y proclama que es la Palabra de Dios la que le impide ordenar mujeres. Parece que la "interpretación" de la Palabra deja de ser obediencia para convertirse en dominio.

2. Ver toda esta increíble historia en J. I. González Faus, La autoridad de la verdad. Momentos oscuros del Magisterio eclesiástico, Santander, 2006², pp. 109-115. Por fortuna, la muerte del papa libró a la Iglesia de lo que san Roberto Bellarmino temía como un descrédito decisivo de la Iglesia católica ante "los herejes". 


\subsection{La verdadera Iglesia de Cristo es una sola y toda la división de las} iglesias convierte a estas en infieles a su Señor. Vaticano II declaró que esta división es un pecado de las iglesias "contraria a la voluntad de Cristo, escándalo para el mundo y dañina para la misión” (UR 1). Pero luego de él, la búsqueda de la unidad ha dejado de ser un acicate que nos urge, para limitarse a una cordialidad en las relaciones oficiales. O se ha declarado simplemente que la iglesia unida "ya existe" y es simplemente la Iglesia católica, y los demás cristianos no son más que herejes que han querido separarse ellos.

En mi pobre opinión, no podemos ser honestos sin reconocer que la imagen de iglesia que permiten adivinar estas diez tesis conciliares dista claramente de la imagen que percibimos en nuestra vida cotidiana. Por eso resulta difícil creer la acusación de que quienes apelan al espíritu del Vaticano II para denunciar la situación actual están manipulando al concilio.

Desde esta eclesiología del Vaticano II se comprende mejor el aparente escándalo del título de este escrito, cuyo significado puede desplegarse en dos nuevas tesis.

1.11. Efectivamente: desde esta sensibilidad, el Vaticano II se negó a aceptar el texto propuesto por la curia romana que decía que la Iglesia de Cristo es (se identifica con) la Iglesia católica y se limitó a decir que la verdadera Iglesia de Cristo "subsiste" en la Iglesia católica (LG 8). Entre "es" y "subiste en" se da la misma distancia que entre la identificación total y la parcial. Subiste quiere decir no solo que puede subsistir también en otras iglesias cristianas, sino, sobre todo, que la Iglesia romana (y todas las iglesias) están obligadas a caminar y a acercarse cada vez más al ideal de la Iglesia de Cristo, por la que el Señor "se entregó para hacerla esposa sin mancha ni arruga" (Ef 5, 27).

No había, pues, escándalo en nuestro título: la Iglesia católico-romana no es la verdadera Iglesia de Cristo porque está obligada a ser mucho más seguidora del Señor Jesús, tanto en sus miembros como también en su cabeza.

Este último punto puede recibir una mayor declaración si analizamos un momento el factor fundamental para la identificación entre la Iglesia de hoy y la de Cristo. Me refiero al concepto de "apostolicidad".

1.12. Teológicamente hablando, la noción de apostolicidad tiene un doble contenido: formal y material. El primero se da por la continuidad histórica en la sucesión; y el segundo, por la continuidad práxica con la llamada de Jesús al seguimiento y con la fidelidad al Señor Jesucristo. Sería absurdo apelar a una mera fidelidad en la línea cronológica si no hay una fidelidad en el seguimiento. 
Pues bien, sin duda es en la Iglesia católico-romana donde mejor se conserva la continuidad histórica, aunque también de una manera condicionada ${ }^{3}$. En ella es donde más garantizada queda la apostolicidad formal. Ello llevó a Newman a convertirse al catolicismo, aunque luego, ya católico, siguiera luchando por dotar a la Iglesia romana de esa apostolicidad material que en buena parte le falta: para que, junto a la apostolicidad de la sucesión, tuviese la Iglesia católica la apostolicidad de la fidelidad al seguimiento.

Así se comprende también la nitidez con la que una voz episcopal (el arzobispo mártir de San Salvador monseñor Romero) apelaba a esta fidelidad al seguimiento como constitutivo de la apostolicidad. Veamos algún ejemplo.

"Una Iglesia que no se une a los pobres para denunciar las injusticias que con ellos se cometen no es la verdadera Iglesia de Jesucristo". Así predicaba monseñor Romero ${ }^{4}$, en línea con Juan Pablo II, que señala el "ser de veras Iglesia de los pobres como verificación de su fidelidad a Cristo" (LE 8). Y es manifiesto el contraste entre la persistencia y la dureza con que la Iglesia romana denuncia otras inmoralidades, y su silencio o su media voz ante este otro que es el mayor pecado de nuestro tiempo.

"Una Iglesia que no sufre persecución, sino que está disfrutando los privilegios y el apoyo de las cosas de la tierra, ¡tenga miedo!, no es la verdadera Iglesia de Jesucristo". O dicho de manera más "pedestre" con el apabullante sentido común del beato J. H. Newman: "Las alfombras, los cojines y la elocuencia no

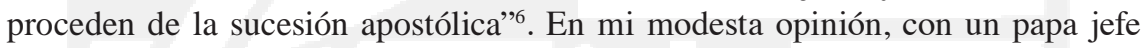
de Estado y unos nuncios con carácter diplomático de embajadores políticos, la Iglesia está disfrutando de los privilegios y el apoyo de las cosas de la tierra. Tendrá todo esto mil ventajas prácticas, pero ellas no resuelven la eterna pregunta de si un fin evangélico justifica unos medios no evangélicos.

3. Pues el cisma de Occidente se resolvió sin llegar a saber cuál de los dos papas en litigio era el verdadero sucesor del anterior; solo se llegó a un acuerdo en el que el nuevo papa Martín V era reconocido como legítimo por el Concilio de Constanza, a cambio de aceptar otras decisiones del Concilio (como el poder de este para decidir la legitimidad de un papa y la obligación de convocar periódicamente concilios de reforma de la Iglesia, que los papas siguientes no cumplieron). Pero el Concilio de Constanza no se pronunció sobre la ilegitimidad sucesoria de los otros dos papas (Benedicto XIII y Juan XXIII), sino que los depuso por impedir la unidad de la Iglesia, apelando al principio medieval de que "el papa que cae en herejía cesa automáticamente de ser papa". Más grave sería la objeción si miramos los dos o tres casos de cisma en la época de las investiduras, cuando quien decidió sobre el verdadero papa no fue un concilio, sino el emperador germano.

4. Homilía del 17 de febrero de 1980 .

5. Homilía del 8 de julio de 1979.

6. Citado en la monumental biografía de K. Ker, p. 188. 
"Una Iglesia que solo condena, que solo mira pecado en los otros y no mira la viga que lleva en el propio [ojo], no es la auténtica Iglesia de Cristo"7. Precisamente la descripción que da aquí Romero reproduce sin saberlo lo que hoy piensa de la Iglesia romana una gran parte de nuestra sociedad, creyente o no.

El arzobispo mártir, tan fiel por otra parte al papado y a los elementos formales de la apostolicidad, no temía hablar de esta manera. Para que se vea la enorme importancia que tiene el seguimiento comunitario de Jesús en la noción de Iglesia. Ello nos lleva a una segunda parte de estas reflexiones.

\section{De la crisis actual a un futuro nunca cerrado}

En las doce tesis anteriores he intentado formular, sin ninguna pretensión de exhaustividad y de manera más bien intuitiva, lo que podría llamarse "espíritu del Vaticano II", es decir, no una mera normativa de reformas, ni siquiera una simple eclesiología (como tratado de la Iglesia), sino, por así decirlo, una "teología de la Iglesia": una visión de la Iglesia desde la voluntad de Dios, o lo que define la identidad de la Iglesia "en la fuerza del Espíritu" (Moltmann), o "lo que el Espíritu dice a las iglesias" (Ap 2, 7.29). El olvido de esta voz del Espíritu está en la raíz de la crisis actual de la Iglesia que, en este sentido, viene ya de lejos. Y marca el único camino por el que la comunidad creyente podrá volver a ser "señal eficaz [sacramento] de salvación".

Digamos en primer lugar que las resistencias o no aceptaciones del Vaticano II, a que hemos aludido antes, no deberían sorprendernos. Los dos concilios que hoy son los más fundamentales en la historia de la Iglesia (el de Nicea y el de Calcedonia) hubieron de soportar una resistencia de décadas tras su aprobación. Ya he hablado de Nicea, donde un buen número de obispos y la mayoría de los emperadores o monarcas eran $\operatorname{arrianos}^{8}$, cosa ya sabida y muy lógica porque el arrianismo (llamado también "monarquismo") concebía el poder supremo de Dios como absolutamente por encima de todos y sin nadie igual a él. Y era muy fácil derivar ese absolutismo desde Dios hasta los poderes terrenos.

En el caso de Calcedonia, los monofisitas derrotados en aquel concilio (porque hacían desaparecer lo humano, diluyéndolo en lo divino) eran un verdadero grupo de presión con alianzas muy fuertes en los diversos palacios y semejante a los que existen en la Iglesia actual. Una forma de "espiritualismo" muy poco espiritual cuando se trata de los medios, y que persiste todavía hoy. Su poder era tal que llevó al emperador Justiniano a convocar un nuevo concilio ecuménico "a fin de congraciarse a los monofisitas mediante la condena de los

7. Homilía del 11 de marzo de 1979.

8. En la España visigótica es fácil recordar la conversión de Recaredo; pero antes había tenido lugar el martirio de san Hermenegildo por orden de su padre Leovigildo. 
teólogos más importantes de la Escuela de Antioquía"9 tachándolos de "impíos", y condenando también a quien llamase hereje a Cirilo de Alejandría, cuyo lenguaje era a veces tan ambiguo como podía serlo por el otro lado el de Teodoro de Mopsuestia o Teodoreto de Ciro...

Pues bien, pasando de la cristología a la eclesiología, cabría decir que hoy asistimos a una especie de arrianismo o de monofisismo eclesiológicos. Pero, más allá de las lecciones de la historia, para comprender lo anterior resulta también imprescindible - y es más importante- una reflexión sobre el Espíritu Santo, que ha sido el gran marginado en la tradición teológica occidental. Pues una Iglesia que se conciba a sí misma como prolongación de la encarnación (Bossuet), se identificará con Cristo y se identificará también ella con el Reino de Dios (valiéndose de la expresión de la autobasileia ${ }^{10}$ que Orígenes utiliza en otro contexto). En una Iglesia así no hay demasiado lugar real ni para el servicio, ni para el Espíritu que es su fuente.

$\mathrm{Y}$ es importante atender a esto porque precisamente tras el Vaticano II, se anunció una era del Espíritu que ha quedado en nada o en sectas. No se trataba entonces de ningún sueño visionario, similar a los de Joaquín de Fiore en la Edad Media. Más bien, había ahí intuición digna de pensarse, que en sus inicios fue muy apoyada por el cardenal Suenens (que había sido uno de los prohombres del concilio), y que vale la pena retomar ahora y considerarla un poco más en dos pasos. Porque, curiosamente, algo parecido cabría sospechar no solo de la historia de la Iglesia, sino también a nivel de la historia humana.

(a) A nivel meramente humano, se sugirió varias veces durante el pasado siglo que la humanidad podría estar entrando en una época nueva, con toda la lentitud que estos cambios tienen en la historia: de una concepción de los seres humanos en la que la dignidad individual apenas era atisbada y la imagen mejor para designar al individuo era la de la oveja en el "rebaño", el género humano fue pasando a un descubrimiento de la dignidad inalienable de lo personal que impedía reducir los individuos a cifras ${ }^{11}$. Y en las horas optimistas del pasado siglo se percibía el nacimiento de una etapa nueva más comunitaria, aunque sin menoscabo del valor personal. Amén de Hegel, que puede ser el hontanar de este modo de concebir, cabe evocar que ya Marx, en un terreno primariamente económico, hablaba de "comunismo grosero", "burguesía" y "comunismo auténtico" como etapas de la historia humana. Y en esta perspectiva se insertarían

9. Introducción al concilio en DH, p. 209.

10. Expresión de Orígenes que identifica a Jesucristo con la totalidad del reino de Dios anunciado por él. Expresión muy difícil de armonizar con otras de las cartas a efesios y colosenses.

11. Este paso se oficializa con el Renacimiento y la modernidad. Pero estaba ya presente en muchas experiencias y páginas del texto bíblico. 
anuncios de socialismos, como el de Teilhard de Chardin (desde una perspectiva meramente evolucionista) o, en el campo más cultural y político, el socialismo de C. Péguy y el personalismo de E. Mounier, con su armonía entre persona y comunidad.

(b) Pues bien: a nivel religioso, cabe trazar una correspondencia con esa evolución. A lo largo de su historia, la humanidad parece haber pasado de una era en que Dios era sobre todo un objeto de conocimiento ${ }^{12}$ (y recordemos que el objeto siempre es algo de lo que te apropias con tu razón), a otra época en que Dios es vivenciado sobre todo como posible interlocutor (época ya anunciada en la Biblia, pero que cuaja más a partir de la modernidad y su descubrimiento del sujeto). Este es en parte el significado de la mística española, pero hay que poner de relieve también la limitación de esa imagen. Pues en nuestra experiencia cotidiana un interlocutor es necesariamente un ser limitado.

Y hoy quizá está alboreando otra época en que concebimos a Dios sobre todo como un "modo de relación" (llamémosle Espíritu, si designamos las dos anteriores como era del Padre - Inaccesible - y del Hijo — que hace presente al Padre-). Pero atención: no se trata de que cada etapa elimine las anteriores: más bien las integra y las sintetiza hegelianamente, al descubrir y consagrar aspectos nuevos muy importantes: Dios está en mi modo de relacionarme y debemos buscarlo $a h i^{13}$. El hecho es que H. Mühlen, uno de los teólogos que estuvieron más cerca de los movimientos pentecostales, hablaba del Espíritu como una "experiencia social de Dios". Y esto se acerca bastante a todo el descubrimiento de Dios que hace Etty Hillesum en su diario.

Huelga decir que esto da una importancia enorme a los intentos pentecostales que surgieron al acabar el Vaticano II y explica el patrocinio antes citado de figuras como el cardenal Suenens.

¿Por qué entonces se han evaporado y han sido tan estériles aquellos movimientos pentecostales? ¿Por qué nos dan la sensación de haberse convertido en guetos de carácter más bien espiritualista, fundamentalistas y ajenos a la realidad? A mi modo de ver, por aquello que en la Edad Media se llamó "la cuestión del filioque": la percepción de que desfiguraba al Espíritu el presupuesto tácito de que procedía solo del Padre, sin tocar para nada la historia a la que ha venido el Hijo. Intentaré explicarlo un poco más.

Fue una verdadera pena que Occidente, contraviniendo el mandato universal de no añadir nada al credo niceno-constantinopolitano, le añadiera la palabra

12. Ser necesario, infinito, o todo aquello que modernamente se ha llamado "ontoteología".

13. Remito al Cuaderno 174 de Cristianisme i Justícia, titulado precisamente Contemplativos en la relación. 
"filioque" (el Espíritu procede del padre "y del Hijo"). Y no porque Occidente no anduviera sobrado de razón en este punto, sino porque tan importante como la razón que podamos tener es el uso que hacemos de ella. Y desobedecer a un concilio ecuménico era la mejor manera de indisponerse con los orientales - como si no hubiera ya bastantes motivos para ello-, y sabiendo además cómo veneraba el Oriente los primeros concilios, precisamente porque se habían celebrado en su suelo. De haber procedido por la vía más fraterna y más evangélica del diálogo, es muy probable que Oriente hubiese aceptado la innovación con la fórmula con que la aceptan hoy muchos orientales ("ex Patre per Filium": el Espíritu procede del Padre, a través del Hijo) y que se considera más exacta que la del "filioque". Al menos, eso es lo que sucedió en el siglo XV en el concilio de Florencia, al que asistieron los orientales.

En cualquier caso, y dejando de lado ahora las raíces históricas, ese olvido del Hijo al hablar de la procedencia del Espíritu, llevó a una falsificación espiritualista y al nacimiento de un gueto de "espirituales". Quizás aquellas corrientes surgieron antes de tiempo: porque primero hacía falta que la Iglesia católica pasara por una profunda "revolución cristológica", por un descubrimiento de Jesús que es el que ha mantenido en pie la fe de muchas gentes fieles al Vaticano II, y a pesar de las posteriores decepciones eclesiásticas ${ }^{14}$. Una vez que esa revolución cristológica se ha llevado a cabo (parcialmente, al menos), es el momento de que renazca (o mejor: simplemente nazca, porque nunca estuvo viva) una revolución pneumatológica. Esta podría ser la tarea para la teología del futuro.

Y esta apelación al Espíritu sirve al menos para hacer ver la importancia del futuro en la historia de la Iglesia. Si no recuerdo mal, K. Rahner dijo una vez que la historia de la Iglesia se dividía en tres etapas: la primera iba desde los orígenes al concilio de Jerusalén (año 50). La segunda iba desde entonces hasta el Vaticano II. Y la tercera comenzaba a partir del Vaticano II. La enorme disparidad de los períodos restó valor e importancia a esta división. Sin embargo, quizás expresaba intuitivamente la gran importancia y la profundidad del cambio que la Iglesia ha de abordar para ser fiel a su misión en el futuro. Evocando otra vez al Espíritu, podríamos decir que la Iglesia oficial está coja porque gira solo en torno a Pedro y no en torno a Pablo, solo en torno a la institución y no en torno al carisma, solo en torno a la tradición y no en torno a la novedad, solo en torno al poder para defender la Palabra y no también en torno a la necesidad de someterse a la Palabra por parte de aquellos mismos que dicen defenderla. Por eso, igual que Pablo reprendió ayer a Pedro porque solo comía con los representantes del judaísmo pretérito y no con los de la libertad nueva de Dios, quizás

14. Aunque es ya muy antiguo y, por tanto, muy incompleto, me permito remitir como síntoma a mi viejo boletín "La revolución de las cristologías", publicado en El Ciervo, en marzo de 1987. 
necesitamos hoy un nuevo Pablo "abortivo" que reprenda al sucesor de Pedro por la unilateralidad excluyente de su trato con los miembros de la Iglesia.

En cualquier caso, y aunque las previsiones para los próximos años no permitan demasiado optimismo, debemos terminar apelando a la confianza porque el futuro no está simplemente en nuestras manos pecadoras, por mucho que se nos llame a trabajar hasta la extenuación: el futuro está simplemente en las manos de Dios. Y aunque el Espíritu ha sido comparado con el viento, que sopla donde quiere, cuando quiere y como quiere, es muy importante que cuando sople no nos encuentre encerrados en casa, sino preparados en las calles de la historia. 